\title{
A framework for 'best practice' in boys' education: key requisite knowledges and Productive Pedagogies
}

\author{
Amanda Keddie \\ Faculty of Education \\ University of Southern Queensland
}

Contact details

Please send any correspondence to:

P.O. Box 140

Darling Heights

QUEENSLAND 4350

\begin{abstract}
In enhancing the social and academic outcomes of boys, positive teacher-student relationships and quality pedagogy that is informed by key research-based understandings and knowledges about gender are positioned as central. The managerial rather than pedagogical focus currently characterizing Queensland (Australia) schools, where the acquisition of basic skills are seen as more important than students' intellectual engagement, can be seen as constraining boys' academic and social development. In examining what might constitute 'best practice' in boys' education, this paper draws on significant socio-cultural research in the area of gender, masculinity and schooling to define the key understandings and knowledges seen as necessary for teachers to effectively construct and apply contextually driven pedagogic strategies to improve educational and social outcomes. The Productive Pedagogies framework of quality
\end{abstract}


teaching and learning (The State of Queensland, 2001) is presented as potentially generative in this regard. This framework is presented here as a way forward for teachers in moving beyond the 'common sense' and prescriptive approaches that continue to drive much of the curriculum and pedagogy in our schools and more specifically many of the programs designed to address the educational needs of boys. In drawing on understandings of gender inequities as a product of social practice, the paper illuminates how teachers can adopt the Productive Pedagogies framework in connecting with boys in intellectually engaging ways to explore their understandings of gender and masculinity and broaden their appreciation of difference and diversity. 


\section{Introduction}

In addressing the issue of gender and educational disadvantage, for some time now, research has been critical of simplistic and essentialist understandings (Collins, Kenway \& McLeod, 2000; Lingard, Martino, Mills \& Bahr, 2002; Teese, Davies, Charlton, \& Polesel, 1995). These understandings have been seen as informing 'common-sense' and under-theorised ways issues of masculinity continue to be addressed in schools. Strategies along the lines of increasing the number of male role models in boys' lives (male teachers and fathers), using more 'masculine' teaching styles, the implementation of single-sex classes, the adoption of authoritarian disciplinary strategies or the use of minimal or non-interventionary approaches are often deployed within simplistic (and invariably biologically deterministic) understandings of gender as difference and opposition (Alloway, 1995; Browne, 1995; Epstein, Elwood, Hey \& Maw, 1998, Gilbert \& Gilbert, 1998; Lingard \& Douglas, 1999). These strategies, while potentially effective in addressing issues of masculinity in schools, can be seen as counterproductive for at least two main reasons. The first being that they are often adopted without "...the requisite critical reflection on the nature of the (strategies) operating and their potential effects" (Lingard et al., 2002, p. 129). In this sense, for example, they can be seen as ineffective because they tend to be prescriptive and fail to account for dynamic and multifaceted contextual factors. The second being that these strategies are often based on recuperating or reinstating an idealized form of conventional and universal white, middle

class and heterosexual masculinity (Connell, 1995). In this sense, for example, they have been seen as implicated in perpetuating, rather than preventing boys' disruptive behaviour 
(Alloway, 1999; Connell, 1995: 2000; Davies, 1993; Keddie, 2003; Mac an Ghaill, 1994).

Positive teacher-student relationships and quality pedagogy which is informed by key research-based understandings and knowledges about gender are positioned as the most significant factors in enhancing the social and academic outcomes of boys (Lingard et al., 2002; Martino \& Meyenn, 2002). In defining what might constitute best practice in boys' education, this paper explores these key understandings and knowledges (Lingard et al., 2002). The paper begins by contextualizing the current predominantly essentialist and under-theorised approaches which continue to underpin programs designed to address the educational needs of boys within a snapshot of Queensland (Australia) classrooms - a teaching and learning climate characterized by low levels of authentic or productive pedagogy and presented here as constraining boys' academic and social development (Lingard et al., 2002; The State of Queensland, 2001). The paper then draws on key socio-cultural research in the area of gender, masculinity and schooling in discussing how boys' social and academic outcomes might be enhanced within a framework of quality pedagogy that recognises and engages with student difference through teaching and learning that is intellectually demanding, socially supportive and connected to students' lives and worlds beyond the classroom (Lingard et al., 2002). Of critical importance, this discussion involves identifying gender knowledges seen as necessary if teachers are to move beyond 'common sense' and prescriptive approaches and effectively construct and apply contextually driven pedagogic strategies to improve the educational and social 
outcomes of both boys and girls (Collins et al., 2000; Lingard et al., 2002; Teese et al., 1995).

\section{Constructing Quality Pedagogy}

The essentialist understandings of gender that continue to drive much of the curriculum and pedagogy in our schools and more specifically many of the programs designed to address the educational needs of boys can be seen as informing invariably simplistic and under-theorised ways issues of masculinity are addressed in schools (Lingard et al., 2002). The existence of these essentialist understandings and under-theorised strategies are better understood when contextualized within the most recent and comprehensive snapshot of Queensland schools (The State of Queensland, 2001). While this research is located within the Queensland context, its conceptual framework as well as its findings, share resonance with and thus relevance to, broader contexts (Newman \& Wehlage, 1995).

The Queensland School Reform Longitudinal Study (QSRLS), a three year examination of the links between classroom practice and improved learning, tells us that teachers generally place greater emphasis on management rather than pedagogy in their classrooms and that while most teachers are concerned about particular issues and problems regarding equity such as gender, they also express a lack of knowledge in terms of how best to address these issues and improve students' behaviour with the application of specific and appropriate pedagogic strategies (The State of Queensland, 2001). 
Teachers' managerial rather than pedagogical focus might also be linked to another QSRLS finding that in terms of importance in improving student learning teachers rate basic skills highest and intellectual engagement and demand lowest. Furthermore, the QSRLS adds that an "overemphasis on basic skills in policy rhetoric, teacher belief, and classroom practice may in fact have counterproductive effects in generating productive student performance" (The State of Queensland, 2001, p. xv).

The QSRLS explains that teachers' general overemphasis on basic skills within a managerial rather than pedagogical focus goes part way in explaining the current climate of Queensland classrooms - a teaching and learning climate that is characterised by low levels of authentic or productive pedagogy. Against this backdrop, while careful to position the responsibility for this teaching and learning climate within a broader institutional picture, the QSRLS urges an extensive refocus to shift teacher attention beyond basic skills to productive pedagogy, particularly in terms of developing students' higher order intellectual skills and citizenship. Among other key recommendations, the QSRLS has identified the following as critical in improving the productive performance and learning outcomes in schools:

- A pressing need to enhance the intellectual demand of pedagogy in Queensland schools (specifically a general lack of higher order thinking, substantive conversation and critical analysis of knowledge);

- The need for more attention to be given to connecting student work to their biographies and the world outside the classroom; 
- The need for more recognition of difference in pedagogies (The State of Queensland, 2001, p. xxv)

Another significant pedagogic concern raised by the QSRLS relates to the area of social justice and the recognition of difference. Generally, despite Queensland's diversity, pedagogy is found to be socially inequitable particularly disadvantaging indigenous students and students of low socio-economic status. As educational research, framed within the principles of social justice, continually makes clear, schools are not neutral sites, indeed the social, political and cultural practices of schools are implicit in constructing, maintaining and perpetuating social inequities. The strong social justice principles underpinning national policy documents (see MCEETYA, 1999) concerning the provision of an inclusive curriculum which challenges rather than accepts social injustice, strengthens the QSRLS recommendation for schools to develop more effective and contextually specific pedagogic strategies designed to improve the learning outcomes of students at educational risk.

In terms of the significance of all this in addressing the educational needs of boys, the current climate of Queensland classrooms can be seen as 'at odds' in terms of 'best practice'. Indeed, a classroom climate of managerial rather than pedagogical focus, characterised by low intellectual quality and limited recognition of difference and connectedness, might be seen as constraining boys' academic and social development. Certainly, this managerial focus might be seen as consistent with “...the first imperative of some teachers when teaching boys (which) appears to be 'controlling' rather than 
teaching them" (Lingard et al., 2002, p. 4). Of particular concern then, given that males continue to "...make up an overwhelming proportion of students experiencing disciplinary problems and school exclusion" is the impact of this climate in terms of constraining boys' social development (Commonwealth of Australia, 2003, p. 4).

Against this backdrop, we might also see the current overemphasis on basic skills as exacerbating boys' 'disciplinary problems'. For it can be seen that, in narrowly defining success and achievement to a focus on basic skills, broader social concerns are positioned as somehow less significant (Mahony, 1999; Pallotta-Chiarolli, 1997).

\section{The importance of quality pedagogy for boys}

As mentioned before, in relation to boys and their engagement with schooling quality pedagogy and positive teacher-student relationships that are informed by sophisticated research-based understandings about gender have been identified as the most significant factors in terms of improving both academic and social outcomes (Martino \& Meyenn, 2002; Lingard et al., 2002). The report Addressing the Educational Needs of Boys (Lingard et al., 2002), identifies the Productive Pedagogies framework within the context of whole school support as potentially generative in enhancing the educational and social outcomes of both boys and girls. The Productive Pedagogies (see Table One for a concise outline) is an increasingly recognised framework of quality teaching and learning which was developed in light of the QSRLS (Hayes, Lingard \& Mills, 2000). Addressing the Educational Needs of Boys argues that this framework recognises and engages with student difference through pedagogies that are intellectually demanding, socially 
supportive and connected to students' lives and worlds beyond the classroom (Lingard et al., 2002). Critically, the report also suggests that a comprehensive approach based on this framework is particularly important for boys and more specifically disengaged boys.

[insert Table One: The Productive Pedagogies]

\section{The Four Dimensions of Productive Pedagogy: \\ Intellectual Quality, Connectedness, Recognition of Difference and Supportive Classroom Environment}

The key element within the dimension of Intellectual Quality involves facilitating students' deep rather than superficial knowledge and understanding of particular topics and issues. Higher order manipulation of information and ideas through substantive conversation that involves critical analysis, reasoning and questioning are of significant importance here. Also critical within this paradigm knowledge is viewed as problematic - as not fixed and unitary but multiple and complex - constructed and maintained by social, political and cultural forces (The State of Queensland, 2001). In terms of meaningful student learning the Productive Pedagogies framework foregrounds the significance of Connectedness. Here enhanced learning occurs through linking particular understandings and knowledges to students' experiences - their lifeworlds and the world beyond the classroom. Inclusivity through the valuing and legitimation of nondominant cultural knowledges underpins the Recognition of Difference dimension. Here the use of narrative (stories, biographies, historical accounts, literacy and cultural texts) is 
seen as powerful in students' coming to understand the politics of difference and in their constructions of affirmative group identities and active citizenship. Against this backdrop a Supportive Classroom Environment characterised by mutual respect fosters students' self-direction and academic engagement with specific activities or tasks. Here teachers' high expectations for all students are important (The State of Queensland, 2001).

\section{Productive Pedagogies ... Productive Boys}

The dimensions of Productive Pedagogy provide us with a useful framework for enhancing boys' academic and social outcomes in comprehensive and contextually sensitive ways. The framework is also useful in helping us to understand why particular strategies for working with boys might be seen as either enabling or constraining 'best practice'. Moreover, the framework's key social justice focus on connecting with students in intellectually engaging ways to broaden understandings of difference and diversity can be seen as strongly resonating with the more complex, contextual and nuanced socio-cultural research in the area of masculinity and schooling (Alloway, Freebody, Gilbert \& Muspratt, 2002; Connell, 2000; Davies, 1993; Gilbert \& Gilbert, 1998; Hickey \& Fitzclarence, 2000; Keddie, 2003; Lingard et al., 2002; Mac an Ghaill, 1994; Martino, 1997: 1999). In moving beyond a prescriptive or superficial adoption of this model, the following looks at the dimensions of Productive Pedagogies with reference to this research. In drawing on this research, the discussion acknowledges the importance of teachers possessing particular requisite knowledges in their critical reflection and construction of socially just pedagogy (Lingard et al., 2002). In moving 
beyond a reinstatement of conventional and essentialist understandings of gender, seen as key in improving the social and academic outcomes of boys (Epstein, 1999), the discussion focuses on the strong social justice tenets informing Productive Pedagogies. In terms of gender justice, the focus is on how teachers can:

...broaden boys' modes of expression to encompass what has been traditionally seen as feminine, instead of progressively limiting their options as they attempt to continue to define themselves in contrast to girls, women and their identification with the feminine (Lingard \& Douglas, 1999, p. 152).

The Productive Pedagogy framework positions Connectedness and Supportive Classroom Environment as critical for quality teaching. In defining what might constitute best practice in boys' education, these dimensions can also be seen as key elements within the masculinities literature (Alloway et al., 2002; Davies, 1993; Lingard et al., 2002). Here enhanced academic and social outcomes are possible through teachers connecting with boys' lifeworlds and the world beyond the classroom. Connecting with boys' lifeworlds in facilitating their exploration of their personal experiences of what it means to be 'masculine' is a particularly significant feature of Boys, Literacy and Schooling (Alloway et al., 2002). This work positions boys' explorations of self as central in improving both educational and behavioural outcomes. The aim here is to enhance boys' understandings of the multiple ways masculinity is constructed, performed, negotiated and navigated in different contexts and how all this impacts variously on their lives (Alloway et al., 2002). 
In discussing how boys might broaden their understandings of self and masculinity Boys, Literacy and Schooling illuminates the importance of teachers expanding their notions and expectations in terms of what it means to be a student but more specifically a male student. Within the context of genuine Connectedness with boys' experiences of navigating the pathways of masculinity and offering boys new ways of 'being a student', the report talks of the significance of a Supportive Classroom Environment characterized by student agency, choice and autonomy. Here teachers increasing their latitude in terms of “...extending opportunities for students to display capabilities and dispositions beyond the normal purview or tolerance of institutionalized schooling" is of key importance (2002, p. 129).

The Productive Pedagogy dimensions of Intellectual Quality and Recognition of Difference, positioned as key elements of quality pedagogy, can also be seen as featuring predominantly within the masculinities literature in terms of enhancing boys' social and academic outcomes (Alloway et al., 2002; Davies, 1993; Lingard et al., 2002). Here boys' deep understandings of masculinity are facilitated through positioning gender(ed) knowledge as problematic in its social, political and cultural construction (Alloway et al., 2002; Davies, 1993; Keddie, 2003; Lingard et al., 2002; MacNaughton, 2000). This research illuminates the importance of facilitating boys' critical analysis of socio-cultural constructions of masculinity in their Recognition of Difference and diversity - seen as central in boys' identification with, and acceptance of, multiple versions of masculinity. In developing boys' affirmative understandings of masculinity which encompass a valuing of non-dominant cultural knowledges, and in particular that which has 
traditionally been seen as feminine, boys' intellectual engagement with identity issues is positioned as central (Lingard \& Douglas, 1999).

\section{Key requisite knowledges and understandings necessary for the effective adoption of pedagogic strategies to improve the academic and social outcomes of boys}

In constructing this environment of Productive Pedagogy within which boys' explorations of masculinity are facilitated in ways that broaden, rather than limit understandings of gender, significant socio-cultural research in the area of masculinities and schooling talks of key requisite knowledges and understandings (Davies, 1993; Lingard et al., 2002; MacNaughton, 2000). Consistent with Lingard et al. (2002), this paper positions these knowledges and understandings as critical if the Productive Pedagogies model is to be adopted to improve boys' academic and behavioural outcomes within a social justice framework.

As pointed out earlier, key research in the area of masculinities and schooling tells us that teachers should expand their notions and expectations in terms of what it means to be a male student and connect with boys' lifeworlds and the world beyond the classroom to facilitate their exploration of what it means to be masculine. To engage in this process, within the social justice frame of Productive Pedagogies, it can be seen that particular teacher understandings of gender might, on the one hand, facilitate a broadening of boys' understandings of masculinity, but on the other hand, confirm and perpetuate boys' 
conventional or essentialist masculinities (as oppositional to that which has traditionally been associated with the feminine).

While teachers might ascribe to the notion that conventional and essentialist understandings of masculinity can be seen as limiting boys' potential both academically and socially, in facilitating a broadening of boys' understandings of masculinity, but in particular in helping boys to construct 'affirmative masculinities' that encompass, rather than reject 'traditional femininity' (Lingard \& Douglas, 1999), it is seen as critical that teachers understand and theorise inequitable gender relations as a product of social practice. Through understanding gender as socially constructed, in terms of being culturally located within a particular point in time, inequitable masculinised and feminised practices can be seen as amenable to change because they are multi-faceted, contextual and dynamic rather than unified or fixed (Davies, 1993; MacNaughton, 2000). Here the gender(ed) system is positioned as a 'non-innocent', rather than pre-given sociopolitical product. This positioning illuminates how inequitable power relations constitute binary understandings of 'masculinity' (read traditional masculinity) as superior and oppositional to 'femininity' (read traditional femininity).

Against this backdrop, teachers can understand why boys “...continue to define themselves in contrast to girls, women and their identification with the feminine" (Lingard \& Douglas, 1999, p. 152). Most importantly, against this backdrop, teachers can understand the significance of engaging with Productive Pedagogies to disrupt the 
gender binary and promote that which has traditionally been seen as feminine (Lingard \& Douglas, 1999).

In facilitating an understanding of gender inequities as a product of partial, contextual and often problematic social practice, students can recognise the historical and cultural specificities of language and meaning and thus make visible the "constitutive force of what is said and what might be" (1993, p. 200). Davies work (1993), for example, demonstrates that within this perspective students can identify the constructed nature of cultural patterns, challenge social inequities and engage in "a collective process of renaming, re-writing (and) re-positioning themselves in relation to coercive structures" (1993, p. 200). Consistent with the call to enhance the intellectual demand of pedagogy (The State of Queensland, 2001) it is the facilitation of boys' deep rather than superficial knowledge and understandings of gender(ed) socio-political procedures, practices and norms through critical analysis, questioning and deconstruction, that is seen as central in addressing the educational needs of boys (Alloway et al., 2002; Davies, 1993; Keddie, 2003; Lingard et al., 2002).

On the other hand, in understanding gender as pre-determined and fixed, gender inequities tend to be taken-for-granted because they are positioned as inevitable - the way things are or ought to be. These understandings tend to homogenise and naturalise difference rather than recognise diversity and in this regard dualistic notions of gender as difference and opposition are maintained. Here essentialist understandings of masculinity which position femininity as inferior, for example, are inevitably legitimized and 
perpetuated rather than problematised. These understandings are what might be seen as informing the 'common-sense' and under theorised approaches that continue to drive much of the curriculum and pedagogy in our schools and more specifically many of the programs designed to address the educational needs of boys (Lingard et al., 2002).

\section{Broadening or constraining boys' understandings of masculinity - an example of how teachers' gender(ed) knowledges are implicated}

A familiar theme within the masculinity and schooling literature acknowledges the significance of teachers connecting with boys' social, emotional and physical investments in bodily expressions of masculinity (Alloway et al., 2002; Commonwealth of Australia, 2002; Fitzclarence \& Hickey, 1998; Lingard \& Douglas, 1999). Boys, Literacy and Schooling (Alloway et al., 2002), for example, talks of teachers enhancing boys’ academic and social performance through interventions that involve active bodily engagement with 'concrete' resources and 'real-world' materials. In discussing classroom intervention strategies, the report talks of the effectiveness of teachers' efforts to produce "...a more comfortable fit between ... pedagogies enacted in their classrooms and boys' enactments of themselves as masculine subjects" (2002, p. 133). In considering the common and often under-theorised assumptions about boys' preferences for more 'masculine' teaching styles including active 'hands on' methods of instruction exploring teachers' possible enactments of this intervention seems especially significant. This exploration is even more significant given that masculinities research continues to express concern regarding the links between boys' investments in bodily expressions of 
masculinity and their enactments of physical domination, violence and aggression (Alloway et al., 2002; Davies, 1993; Fitzclarence \& Hickey, 1998; Lingard \& Douglas, 1999). Within the context of the call for teachers to connect with boys to expand their notions and expectations of what it means to be a male student then, defining what kind of male student becomes central (Alloway et al., 2002; Commonwealth of Australia, 2002).

The following discusses this intervention (of increasing boys' bodily engagement with 'concrete' resources and 'real-world' materials) to illuminate how the gender(ed) knowleges and understandings (about what it means to be a male student) that inform teachers' pedagogies are strongly implicated in shaping boys' understandings of masculinity. The following draws on the Productive Pedagogies model to illustrate this in two key ways. The first key way describes how teachers can embrace this intervention in ways that enable the facilitation of boys' broadening their understandings of masculinity. The second key way describes how teachers' use of this intervention can work in ways that thwart gender justice through confirming and reinstating limited understandings of gender.

A teacher who understands gender inequities as a product of social practice and thus recognises the importance of disrupting the gender binary might draw on the dimensions of Productive Pedagogy in ways that facilitate boys' valuing of what has been traditionally seen as feminine (Lingard \& Douglas, 1999). Here, for example, learning experiences might draw on (traditionally feminine) bodily expressive modes such as 
drama and dance to explore the 'real world' and 'concrete' materials of popular culture (Alloway et al., 2002). In this activity, for example, boys could be challenged to investigate how gender is represented within their own sphere of popular culture. Specifically, students could select a particular cultural artefact (examples might be a video game, magazine or toy) and analyse how gender is represented. Here students could examine issues of gender and social power in terms of privilege and marginalisation and look at how these gender(ed) representations might be reworked to be more inclusive of difference. The 'findings' of this investigation could then be presented as a role-play drama or dance. In terms of quality pedagogy, we can see this activity as potentially generative in relation to broadening boys' understandings of masculinity through an engagement with active, 'hands-on' and embodied experiences that draw on 'real world' materials. It is connected to boys' lifeworlds and the world beyond the classroom (Connectedness); it is intellectually engaging in terms of using the skills of critical analysis in viewing knowledge as problematic and facilitating deep understanding of issues and concepts (Intellectual Quality); it recognises difference through looking at issues of privilege, marginalisation and inclusion and fosters active citizenship through acknowledging and legitimising non-dominant cultural knowledges (Recognition of Difference); and, it can be seen to facilitate student agency, choice and autonomy (Supportive Classroom Environment).

In terms of adopting the intervention to increase boys' active bodily engagement this learning experience can be seen as accounting for the nature of this strategy and its potential effects (Lingard et al., 2002). To explain further, the potential effects of 
increasing boys' bodily engagement or physical activity, might involve amplifying the masculine conventions of power, strength and domination (Connell, 2000). To this end, the activity might be seen as disrupting the links between boys' investments in bodily expressions of masculinity as enacted through power, strength and physical domination through channelling these bodily investments into the traditionally feminine bodily expressive modes of drama and dance. This disruption, in conjunction with the critical analysis and reworking of the gender(ed) representations in boys' popular culture (which often display masculine images of power, strength and domination), can be seen as helping to broaden rather than constrain boys' understandings of gender through offering alternative versions of masculinity (Davies, 1993; Lingard \& Douglas, 1999).

A teacher who understands gender difference as a pre-given inevitability might also draw on the framework of Productive Pedagogy in their efforts to increase boys' opportunities for active bodily engagement, however, within what might be seen as a 'common sense' approach to gender, the nature of this strategy and its potential effects would be seen quite differently to the previous example. Most significantly, if gender inequities are seen as inevitable - the way things are or ought to be - then it would not be seen as important to disrupt the gender binary nor to broaden boys' understandings of masculinity to encompass traditional femininity with regard to bodily engagement. It would be more likely to be seen as important to identify particular bodily expressions as specific or unique to boys per se and to draw on these expressions in the construction of learning experiences. Here, while students might engage in a similar learning experience to the one just described, from a paradigm of thinking about gender along essentialist lines, the 
teacher is likely to draw on the traditionally masculine bodily expressive modes associated with physical strength, power and competition (Connell, 2000) rather than encourage boys to express themselves in 'non-dominant', and more aesthetic ways. Moreover, within this paradigm, the teacher is not likely to facilitate a problematising of the gender representations in boys' popular culture.

Without seeing inequitable gender relations as a construction of non-innocent sociopolitical practice, the binary understandings equating masculinity with power and domination and femininity with powerlessness and subordination (certainly a feature of boys' popular culture) are likely to be naturalised and to remain taken-for-granted. We still might see the four dimensions of Productive Pedagogy in this version of the activity - it is clearly Connected to students and in this regard, like the previous version, can be seen as facilitating student agency, choice and autonomy (Supportive Classroom Environment). However, while the activity may also acknowledge non-dominant culture through the critical analysis of knowledge (Intellectual Quality and Recognition of Difference), most significantly, gender knowledges are not critically analysed nor are they presented as problematic (Intellectual Quality). Further, there is no acknowledgement or appreciation of non-dominant cultural knowledges about gender (Recognition of Difference). Against this backdrop, we can see that without the requisite teacher knowledges to facilitate a challenging of the inequitable gender representations of boys' popular culture, these representations (which are likely to be idealised and hypermasculine), and the asymmetrical power relations that constitute them, remain unchallenged and legitimised. 


\section{Concluding Remarks}

In examining how quality pedagogy might constitute best practice in boys' education, this paper affirms the importance of teachers drawing on key research-based understandings and knowledges about gender. The Productive Pedagogies model is presented as potentially generative in enhancing boys' social and academic outcomes. In facilitating a broadening of boys' understandings of masculinity, but in particular in helping boys to construct 'affirmative masculinities' that encompass, rather than reject 'traditional femininity', teachers' understandings of inequitable gender relations as a product of social practice, are positioned as critical. Through understanding the gender(ed) system as a 'non-innocent', rather than pre-given socio-political product, the power inequities that constitute binary understandings of 'masculinity' as superior and oppositional to 'femininity' can be seen as unjust and amenable to challenge and reconstitution. These gender knowledges are seen as instrumental in teachers moving beyond common sense interventions, that tend to reinstate gender injustice, in their adoption of a comprehensive and socially just approach to Productive Pedagogies.

Within a framework of Productive Pedagogy, which draws on these key knowledges and understandings about gender, best practice in boys' education might be defined within a paradigm that acknowledges: 
- The importance of a critical and reflective focus on pedagogy and, in particular, its implication in enabling and constraining academic and social outcomes;

- The significance of this for boys in terms of how the gender(ed) knowledges and understandings that inform teachers' pedagogies are implicated in ignoring and perpetuating, or challenging and reworking, gender inequities;

- The pressing need to increase the intellectual demand of pedagogy, particularly facilitating students' deep knowledge of issues and concepts through developing skills of higher order thinking and critical analysis;

- The significance of this for boys in facilitating their problematising of gendered knowledge and restrictive understandings of masculinity in enhancing their understandings of the multiple ways masculinity is constructed, performed, negotiated and navigated in different contexts and how all this impacts on their lives (Alloway et al., 2002);

- The need for connecting learning experiences to students' life-worlds and the world beyond the classroom;

- The significance of this for boys in terms of enhancing academic and social outcomes through connecting with and engaging their interests, opinions, cultures, emotions and sense of self (Alloway et al., 2002);

The importance of recognising difference and valuing non-dominant cultural knowledges;

- The significance of this for boys in broadening their understandings of what constitutes 'desirable' masculinity and in particular in their 
acceptance of alternative (non-dominant cultural) versions of masculinity and their generation of more affirmative identities;

- The importance of maintaining a socially supportive classroom environment characterised by mutual respect which fosters students' self-direction and academic engagement;

- The significance of this for boys in constructing positive teacher-student relationships which, along with quality pedagogy, are positioned as central in improving academic and social outcomes. 


\section{References}

Alloway, N. (1995). Foundation Stones: The Construction of Gender in Early Childhood. Carlton: Curriculum Corporation.

Alloway, N., Freebody, P., Gilbert, P. \& Muspratt, S. (2002). Boys, literacy and schooling: expanding the repertoires of practice. Canberra: Commonwealth Department of Education, Science and Training.

Alloway, N. (1999). Surveillance or Personal Empowerment? Macro and Micropolitics of gender and schooling. In B. Kamler (Ed.), Constructing Gender and Difference. New Jersey: Hampton Press.

Browne, R. (1995). Schools and the construction of masculinity. In R. Browne \& R. Fletcher (Eds.), Boys In Schools. Lane Cove: Finch Publishing.

Collins, C., Kenway, J., \& McLeod, J. (2000a). Factors Influencing the Educational Performance of Males and Females in School and their Initial Destinations after Leaving School: A Project Funded by the Commonwealth Department of Education, Training and Youth Affairs. Canberra.

Connell, R. (1995). Masculinities. St Leonards: Allen \& Unwin.

Connell, R. (1996). Teaching the boys: new research on masculinity, and gender strategies for schools. Teachers College Record, 98(2), 206-235.

Connell, R. W. (2000). The Men and The Boys. St. Leonards: Allen \& Unwin.

Commonwealth of Australia (2002). Boys: Getting it right, Report on the inquiry into the education of boys, Canberra: Author. 
Commonwealth of Australia (2003). Educating Boys: Issues and Information, Canberra: Author.

Davies, B. (1993). Shards of Glass. St Leonards: Allen \& Unwin.

Epstein, D., Elwood, J., Hey, V. \& Maw, J. (Eds.) (1998), Failing Boys? Issues in Gender and Achievement. Buckingham: Open University Press.

Epstein, D. (1999). Real boys don't work: 'underachievement', masculinity and the harassment of 'sissies'. In D. Epstein \& J. Elwood \& V. Hey \& J. Maws (Eds.), Failing Boys: Issues in Gender and Achievement. London: Open University Press.

Gilbert, R. \& Gilbert, P. (1998). Masculinity Goes to School, St Leondards: Allen \& Unwin.

Fitzclarence, L., \& Hickey, C. (1998). Learning to rationalise abusive behaviour through football. In C. Hickey \& L. Fitzclarence \& R. Matthews (Eds.), Where The Boys Are. Geelong: Deakin University.

Hayes, D., Lingard, B. \& Mills, M. (2000). Productive Pedagogies. Education Links 60

Hickey, C., \& Fitzclarence, L. (1997). Masculinity, violence and football. Changing Education: a journal for teachers and administrators, 4(2 \& 3), 18-21.

Hickey, C., \& Fitzclarence, L. (2000) Peering at the individual: Problems with trying to teach young males' not to be like their peers. Australian Educational Researcher. 27(1), 71-91.

Lingard, B., \& Douglas, P. (1999). Men Engaging Feminisms. Buckingham: Open University Press. 
Lingard, B., Martino, W., Mills, M. \& Bahr, M. (2002). Addressing the Educational Needs of Boys - Strategies For Schools. Canberra: Commonwealth Department of Education, Science and Training.

Mac an Ghaill, M. (1994). The Making of Men. Buckingham: Open University Press. MacNaughton, G. (2000). Rethinking Gender in Early childhood Education, St. Leonards: Allen \& Unwin.

Mahony, P. (1999). Girls will be girls and boys will be first. In D. Epstein, J. Elwood, V. Hey and J. Maws (Eds.), Failing Boys: Issues in Gender and Achievement. London: Open University Press.

Martino, W. (1997). A bunch of arseholes: exploring the politics of masculinity for adolescent boys in schools. Social Alternatives, 16(3), 39-43.

Martino, W. (1999). Cool boys, party animals, squids and poofters. British Journal of Sociology of Education, 20(2), 239-264.

Martino, W. \& Meyenn, B. (2002). War, guns and cool, tough things': interrogating single-sex classes as a strategy for engaging boys in English. Cambridge Journal of Education 32 (3) 303-324.

MCEETYA (1999) The Adelaide Declaration on National Goals for Schooling in the Twenty - First Century, Victoria: Author.

Newman, F. \& Wehlage, G. (1995). Successful School Restructuring: A Report to the Public and Educators, University of Wisconsin: Center of Organisation and Restructuring of Schools. 
Pallotta-Chiarolli, M. (1997). We want to address boys' education but... In J. Kenway (Ed.), Will Boys be Boys? Deakin West: Australian Curriculum Studies Association.

Teese, R., Davies, M., Charlton, R., \& Polesel, J. (1995). Who Wins at School? Canberra: Australian Government Publishing Service.

The State of Queensland (Department of Education) (2001). The Queensland School Reform Longitudinal Study, Brisbane: Author. 


\section{Table One: The Productive Pedagogies}

\begin{tabular}{|c|c|}
\hline \multicolumn{2}{|r|}{ INTELLECTUAL QUALITY } \\
\hline Higher order thinking & Are higher order thinking and critical analysis occurring? \\
\hline Depth of knowledge & $\begin{array}{l}\text { Does the lesson cover central concepts and their complex relations in } \\
\text { any depth, detail or level of specificity? }\end{array}$ \\
\hline $\begin{array}{l}\text { Depth of students' } \\
\text { understanding }\end{array}$ & $\begin{array}{l}\text { Do the work and response of the students provide evidence of } \\
\text { understanding of concepts or ideas? }\end{array}$ \\
\hline Substantive conversation & $\begin{array}{l}\text { Does classroom talk break out of the initiation/response evaluation } \\
\text { pattern and lead to sustained dialogue between students, and between } \\
\text { teachers and students? }\end{array}$ \\
\hline Knowledge as problematic & $\begin{array}{l}\text { Are students critiquing and second-guessing texts, ideas and } \\
\text { knowledge? }\end{array}$ \\
\hline Meta-language & $\begin{array}{l}\text { Are aspects of language, grammar, and technical vocabulary being } \\
\text { foregrounded? }\end{array}$ \\
\hline \multicolumn{2}{|r|}{ CONNECTEDNESS } \\
\hline Knowledge integration & Does the lesson range across diverse fields, disciplines and paradigms? \\
\hline $\begin{array}{l}\text { Link to background } \\
\text { knowledge }\end{array}$ & Is there an attempt to connect with students' background knowledge? \\
\hline $\begin{array}{l}\text { Connection to the world } \\
\text { beyond the classroom }\end{array}$ & $\begin{array}{l}\text { Do lessons and the assigned work have any resemblance or connection } \\
\text { to real life contexts? }\end{array}$ \\
\hline Problem-based curriculum & $\begin{array}{l}\text { Is there a focus on identifying and solving intellectual and/or real- } \\
\text { world problems? }\end{array}$ \\
\hline \multicolumn{2}{|r|}{ SUPPORTIVE CLASSROOM ENVIRONMENT } \\
\hline $\begin{array}{l}\text { Students' direction of } \\
\text { activities }\end{array}$ & $\begin{array}{l}\text { Do students have any say in the pace, direction or outcomes of the } \\
\text { lesson? }\end{array}$ \\
\hline $\begin{array}{l}\text { Social support for student } \\
\text { achievement }\end{array}$ & Is the classroom a socially supportive, positive environment? \\
\hline Academic engagement & Are students engaged and on-task? \\
\hline $\begin{array}{l}\text { Explicit quality } \\
\text { performance criteria }\end{array}$ & Are criteria for student performance made explicit? \\
\hline Student self-regulation & $\begin{array}{l}\text { Is the direction of student behaviour implicit and self-regulatory or } \\
\text { explicit? }\end{array}$ \\
\hline \multicolumn{2}{|r|}{ RECOGNITION OF DIFFERENCE } \\
\hline $\begin{array}{l}\text { Cultural knowledge values } \\
\text { cultures }\end{array}$ & Are diverse cultural knowledges brought into play? \\
\hline $\begin{array}{l}\text { Public representation of } \\
\text { inclusive participation }\end{array}$ & $\begin{array}{l}\text { Are deliberate attempts made to increase the participation of all } \\
\text { students of different backgrounds? }\end{array}$ \\
\hline Narrative & Is the teaching principally narrative, or is it expository? \\
\hline $\begin{array}{l}\text { Group identities in learning } \\
\text { community }\end{array}$ & Does teaching build a sense of community and identity? \\
\hline Active Citizenship & Are attempts made to foster active citizenship? \\
\hline
\end{tabular}

(The State of Queensland 2001) 
